\begin{tabular}{l} 
Efficient $\mathrm{Vol}$ 1 (3) (2018): 191-199 DOI: https://doi.org/10.15294/efficient.vii3.27879 \\
$\begin{array}{c}\text { Indonesian Journal of Development Economics } \\
\text { https://journal.unnes.ac.id/sju/index.php/efficient }\end{array}$ \\
\hline
\end{tabular}

\title{
Efisiensi Faktor-Faktor Produksi Usaha Tani Ubi Kayu di Kabupaten Pati
}

\author{
Azka Fadlli', Prasetyo Ari Bowo ${ }^{2}$ \\ Jurusan Ekonomi Pembangunan,Fakultas Ekonomi, Universitas Negeri Semarang \\ Permalink/DOI: https://doi.org/10.15294/efficient.vii3.27879
}

Received: April 2018 ; Accepted: July 2018 ; Published: October 2018

\begin{abstract}
Harvest area and production of cassava in Pati Regency at 2014 are enhancement, but productivity of cassava has decrease.The purpose of this study to determine the technical efficiency, price efficiency and the economic efficiency of the use of factors of production in cassava farming in Pati regency. The independent variables in this study are land area, labor, fertilizer, and seed. While the production of cassava as the dependent variable. The analytical method used is the analysis of technical efficiency, price efficiency and economic efficiency with software frontier $41 \mathrm{c}$ tools. The results showed that the use of factors of production in cassava farming in Pati regency yet achieved technical efficiency, price efficiency and economic efficiency. The advice can be given is the use of production factors in the cultivation of cassava in Pati regency can be combined and optimized through the addition of production factors of labor and seedlings, as well as reducing fertilizer production factor.
\end{abstract}

Keywords: Efficiency, Production Factors, Cassava Farming

\begin{abstract}
Abstrak
Luas Panen dan produksi ubi kayu di Kabupaten tahun 2014 mengalami peningkatan, tetapi produktivitas ubi kayu mengalami penurunan.Tujuan penelitian ini untuk mengetahui efisiensi teknis, efisiensi harga dan efisiensi ekonomi penggunaan faktor-faktor produksi pada usahatani ubi kayu di Kabupaten Pati. Variabel independen dalam penelitian ini adalah luas lahan, tenaga kerja, pupuk dan bibit, sedangkan produksi ubi kayu sebagai variabel dependen. Metode analisis yang digunakan adalah analisis efisiensi teknis, efisiensi harga dan efisiensi ekonomi dengan alat bantu software frontier 41c. Hasil penelitian menunjukkan bahwa penggunaan faktorfaktor produksi pada usahatani ubi kayu di Kabupaten Pati belum tercapai efisiensi teknis, efisiensi harga dan efisiensi ekonomi. Saran yang dapat diberikan yaitu penggunaan faktor-faktor produksi pada usahatani ubi kayu di Kabupaten Pati dapat dikombinasikan dan dioptimalkan melalui penambahan faktor produksi tenaga kerja dan bibit, serta mengurangi faktor produksi pupuk.
\end{abstract}

Kata Kunci: Efisiensi, Faktor-Faktor Produksi, Usahatani Ubi Kayu

How to Cite: Fadlli, A., \& Bowo, P. (2018). Efisiensi Faktor - Faktor Produksi Usaha Tani Ubi Kayu di Kabupaten Pati. EFFICIENT Indonesian Journal of Development Economics, 1(3), $191-199$. https://doi.org/10.15294/efficient.vii3.27879

(C) 2018 Semarang State University. All rights reserved

\footnotetext{
Alamat Korespondensi :

Alamat: Gedung L2 Lantai 2 FE Unnes

Kampus Sekaran, Gunungpati, Semarang, 50229

E-mail : efficientjournal@gmail.com
} 


\section{PENDAHULUAN}

Pertanian merupakan salah satu sektor utama yang menopang kehidupan masyarakat, karena sektor pertanian menjadi mata pencaharian sebagian besar penduduk Indonesia. Berangkat dari hal tersebut maka pertanian merupakan salah satu sektor penopang perekonomian nasional, artinya bahwa sektor pertanian memegang peranan penting dan seharusnya menjadi penggerak dari kegiatan perekonomian negara (Setiawan dan Prajanti, 2011:69).

Menurut BPS sektor pertanian terbagi dalam 5 subsektor, yaitu subsektor tanaman pangan, subsektor tanaman perkebunan, subsektor peternakan, subsektor kehutanan dan subsektor perikanan. Salah satu jenis pertanian dalam subsektor tanaman pangan adalah pertanian ubi kayu, berdasarkan data BPS (2014) ubi kayu merupakan makanan konsumsi ketiga terbesar di Indonesia setelah beras dan terigu yaitu sebesar 6,78\% per kapita per tahun. Berdasarkan data Food and Agricultural Organization of the United Nations (FAO) pada tahun 2014 Indonesia merupakan negara penghasil ubi kayu terbesar ketiga dunia dengan produksi sebesar 25 juta ton setelah Nigeria dan Thailand.

Ubi kayu memiliki beragam produk turunan yang sangat prospektif dan berkelanjutan baik pangan maupun nonpangan. Pada bidang pangan ubi kayu umumnya diolah menjadi tepung tapioka, tepung tapioka yang diproses lebih lanjut dapat dijadikan tepung kasava pengganti terigu, pati yang dihidrolis dapat menghasilkan sirup glukosa. Sementara untuk non pangan ubi kayu dimanfaatkan sebagai bahan baku kosmetik, bioethanol, bahan kimia, dan industri tekstil. Indonesia memiliki beberapa provinsi penghasil ubi kayu, salah satunya adalah Provinsi Jawa Tengah. Berdasarkan data Badan Pusat Statistik (BPS) pada tahun 2014 Provinsi Jawa Tengah memiliki luas panen ubi kayu seluas 153.201 hektare, produksi ubi kayu sebesar 3,8 juta ton dan produktivitas sebesar 259,65 ku/ha. Jawa Tengah memiliki beberapa daerah penghasil ubi kayu terbesar, antara lain Kabupaten Wonogiri, Kabupaten Pati, Kabupaten Jepara, Kabupaten Wonosobo dan Kabupaten Banjarnegara. Kondisi luas panen, produksi dan produktivitas ubi kayu di Provinsi Jawa Tengah tahun 2013-2014 dapat dilihat pada tabel 1 (terlampir di bagian lampiran).

Tabel 1 menunjukkan bahwa pada tahun 2013 dan 2014 terdapat 5 kabupaten yang memiliki produksi ubi kayu terbesar di Provinsi Jawa Tengah. Kabupaten Pati menempati posisi kedua dengan luas panen ubi kayu seluas 16.163 hektare pada tahun 2013 dan mengalami peningkatan pada tahun 2014 menjadi 17.871 hektare, peningkatan luas panen tersebut diikuti peningkatan produksi sebesar 74.475 ton pada tahun 2014 dari tahun 2013 sebesar 69.833 ton. Akan tetapi produktivitas ubi kayu di Kabupaten Pati mengalami penurunan pada tahun 2014 sebesar 416,73 kw/ha dari tahun 2013 sebesar 432,05 kw/ha. Peningkatan luas panen dan produksi yang justru menurunkan produktivitas ubi kayu hanya terjadi di Kabupaten Pati dari 5 kabupaten penghasil produksi ubi kayu terbesar di Provinsi Jawa Tengah pada tahun 2014. Selain itu, peningkatan luas panen dan produksi yang disertai dengan penurunan produktivitas pada 
pertanian di Kabupaten Pati pada tahun 2014 hanya terjadi pada pertanian ubi kayu jika dibandingkan dengan tiga jenis pertanian yang memiliki produksi terbesar, untuk lebih jelasnya dapat dilihat pada tabel 1.

Pada tabel 2. menunjukkan bahwa pada tahun 2013-2014 ada 3 jenis pertanian yang memiliki produksi terbesar di Kabupaten Pati yaitu pertanian ubi kayu, jagung dan padi, akan tetapi peningkatan luas panen dan produksi yang disertai penurunan produktivitas pada tahun 2014 hanya terjadi pada pertanian ubi kayu.

Tujuan penelitian ini adalah untuk menganalisis pengaruh faktor produksi luas lahan, tenaga kerja, pupuk dan bibit terhadap produksi ubi kayu serta menganalisis efisiensi teknis, efisiensi harga dan efisiensi ekonomi penggunaan faktor-faktor produksi pada usahatani ubi kayu di Kabupaten Pati.

Tabel 2. Luas Panen, Produksi dan Produktivitas Padi, Jagung dan Ubi Kayu di Kabupaten Pati Tahun 2013-2014

\begin{tabular}{llll}
\hline Jenis Pertanian & Tahun & 2013 & 2014 \\
\hline \multirow{3}{*}{ Padi } & Luas Panen (Ha) & 103.999 & 92.559 \\
& Produksi (Ton) & 589.202 & 497.071 \\
& Produktivitas (Kw/ha) & 93,36 & 91,92 \\
Jagung & Luas Panen (Ha) & 17.722 & 20.751 \\
& Produksi (Ton) & 96.028 & 126.411 \\
& Produktivitas (Kw/ha) & 54,19 & 60,92 \\
Ubi Kayu & Luas Panen (Ha) & 16.163 & 17.871 \\
& Produksi (Ton) & 69.833 & 74.475 \\
& Produktivitas (Kw/ha) & 432,05 & 416,73 \\
\hline
\end{tabular}

Sumber : BPS Kabupaten Pati (2015)

\section{METODE PENELITIAN}

Penelitian ini menggunakan pendekatan kuantitatif. Pendekatan kuantitatif dituntut menggunakan angka mulai dari pengumpulan, penafsiran serta hasilnya. Populasi dalam penelitian ini adalah petani yang menanam ubi kayu di lahan miliknya maupun lahan sewa dari pemilik lahan yang berjumlah 3114. Teknik sampel yang digunakan dalam penelitian ini adalah Cluster Sampling (Area Sampling).

Sehingga pada tahap pertama dipilih dua kecamatan di Kabupaten Pati sebagai lokasi penelitian, yaitu Kecamatan Tlogowungu dan Kecamatan Gembong. Tahap kedua dipilih 3 desa dengan jumlah proporsi petani ubi kayu terbesar di Kecamatan Tlogowungu dan Kecamatan Gembong. Penentuan sampel dalam penelitian ini mengacu pada persamaan slovin, sehingga diperoleh sampel petani ubi kayu di Desa Cabak sebanyak 28 orang, Desa Tajungsari sebanyak 27 orang, Desa Tlogosari sebanyak 26 orang, Desa Bermi sebanyak 7 orang, Desa Pohgading sebanyak 4 orang, Desa Gembong sebanyak 5 orang. Data dalam 
Penelitian ini meliputi data primer yang diperoleh dari hasil wawancara kepada responden petani ubi kayu yang berjumlah 97 orang. Sedangkan data skunder diperoleh dari dokumen, catatan, jurnal dan situs internet yang dimiliki dinas atau instansi terkait.

Pengumpulan data dalam penelitian ini diperoleh dari wawancara dan dokumentasi. Wawancara digunakan untuk mencari data primer dalam penyusunan penelitian ini. Metode wawancara dilakukan kepada 97 responden petani ubi kayu yang dilaksanakan pada bulan November hingga bulan Desember tahun 2016. Dokumentasi digunakan untuk mencari data skunder dari dokumen, catatan, jurnal dan situs internet yang diperoleh dari BPS Jawa Tengah, BPS Kabupaten Pati, Balai Penyuluhan Pertanian (BPP) Kecamatan Tlogowungu dan Kecamatan Gembong. Model matematis fungsi produksi usahatani ubi kayu dengan pendekatan fungsi produksi stokastik frontier dalam penelitian ini adalah:

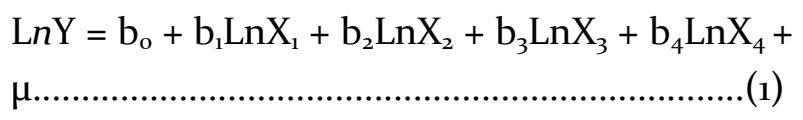

Keterangan :

$\mathrm{L} n \mathrm{Y}=\log$ natural variabel hasil produksi $(\mathrm{Kg})$

$\mathrm{b}_{\mathrm{o}} \quad=$ parameter

$\mathrm{LnX}_{1}=\log$ natural variabel luas lahan $\left(\mathrm{m}^{2}\right)$

$\mathrm{LnX}_{2}=\log$ natural variabel tenaga kerja (HOK)

$\mathrm{LnX}_{3}=\log$ natural variabel pupuk $(\mathrm{Kg})$

$\mathrm{LnX}_{4}=\log$ natural variabel bibit (Batang)

$\mathrm{b}_{1}-\mathrm{b}_{3}=$ koefisien regresi

$\mu \quad=$ residu
Efisiensi teknis dalam penelitian ini dapat diketahui dengan menggunakan alat bantu olah data software Frontier Version 4.1.c. Jika nilai efisiensi teknis sama dengan satu, maka penggunaan input usahatani ubi kayu sudah efisien berdasarkan aspek teknis. Jika nilai efisiensi teknis tidak sama dengan satu, maka penggunaan input usahatani ubi kayu belum efisien berdasarkan aspek teknis.

Efisiensi harga dalam penelitian ini dapat diketahui dengan menggunakan rumus persamaan sebagai berikut:

$\mathrm{EH}=\frac{b \cdot \bar{Y} P_{\bar{y}}}{\bar{X} \cdot P_{\bar{x}}}$

$b$ menunjukkan elastisitas produksi, $\bar{Y}$ menunjukkan rata-rata produksi ubi kayu, $\mathrm{P}-$ menunjukkan harga produksi ubi kayu ratarata, $\bar{X}$ menunjukkan rata-rata faktor produksi $\mathrm{X}$ dan $\mathrm{P}_{x}-$ menunjukkan harga input rata-rata Berdasarkan penghitungan menggunakan rumus (1) maka dapat diketahui, apabila $\mathrm{EH}=1$, artinya bahwa penggunaan faktor produksi usahatani ubi kayu sudah tercapai efisiensi harga. EH > 1, artinya bahwa penggunaan faktor produksi usahatani ubi kayu belum tercapai efisiensi harga. $\mathrm{EH}<1$, artinya bahwa penggunaan faktor produksi usahatani ubi kayu tidak tercapai efisiensi harga.

Efisiensi ekonomi dalam penelitian ini dapat diiketahui dengan cara mengalikan hasil perhitungan efisiensi teknis dan efisiensi harga 
dengan rumus sebagai berikut:

$\mathrm{EE} \quad=\mathrm{ET} \times \mathrm{EH}$

Keterangan:

$\begin{array}{ll}\mathrm{EE} & =\text { Efisiensi Ekonomi } \\ \mathrm{ET} & =\text { Efisiensi Teknis } \\ \mathrm{EH} & =\text { Efisiensi Harga }\end{array}$

Berdasarkan perhitungan menggunakan rumus (2) maka dapat diketahui, apabila $\mathrm{EE}=$ 1, artinya efisiensi ekonomi usaha tani ubi kayu tercapai, kombinasi input sudah tepat. EE > 1, artinya efisiensi ekonomi usahatani ubi kayu belum tercapai, maka penggunaan input dapat dilakukan penambahan. EE $<1$, artinya efisiensi ekonomi usahatani ubi kayu tidak tercapai, maka penggunaan input dapat dilakukan pengurangan.

\section{HASIL DAN PEMBAHASAN}

Hasil estimasi model fungsi produksi usahatani ubi kayu dengan pendekatan fungsi produksi stokastik frontier dalam penelitian ini adalah:

$$
\begin{aligned}
& \text { Model }=\operatorname{LnY}=b_{0}+b_{1} \operatorname{LnX} 1+b_{2} L_{n} X_{2} \\
& +\mathrm{b}_{3} \mathrm{LnX}_{3}+\mathrm{b}_{4} \mathrm{LnX}_{4}+ \\
& \text { H............(4) } \\
& \begin{aligned}
\text { Estimasi }= & \operatorname{LnPd}=1,4506+0,0173 \mathrm{LnLh} \\
& +0,3451 \quad \mathrm{LnTk}+0,0545 \\
& \operatorname{LnPu}+0,7080 \mathrm{LnBt}
\end{aligned}
\end{aligned}
$$

Keterangan :

$\begin{array}{ll}\text { LnPd } & \text { : Produksi } \\ \text { LnLh } & : \text { Luas Lahan } \\ \text { LnTk } & : \text { Tenaga Kerja } \\ \text { LnPu } & : \text { Pupuk } \\ \text { LnBt } & \text { : Bibit }\end{array}$

Berdasarkan model tersebut maka dapat dijelaskan bahwa penambahan input luas lahan sebesar $1 \%$ akan meningkatkan produksi sebesar 0,0174\% dengan asumsi cetris paribus. Penambahan input tenaga kerja sebesar $1 \%$ akan meningkatkan produksi sebesar $0,3451 \%$ dengan asumsi cetris paribus. Penambahan input pupuk sebesar $1 \%$ akan meningkatkan produksi sebesar $0,0545 \%$ dengan asumsi cetris paribus. Penambahan input bibit sebesar $1 \%$ akan meningkatkan produksi sebesar $0,708 \%$.

Hasil penghitungan efisiensi teknis diperoleh nilai rata-rata sebesar o,9976, sehingga dapat dijelaskan bahwa usahatani ubi kayu di Kabupaten Pati belum efisien berdasarkan aspek teknis. Kondisi tersebut terjadi karena petani ubi kayu belum mampu mengkombinasikan penggunaan faktor produksi luas lahan, tenaga kerja, pupuk dan bibit untuk mendapatkan produksi ubi kayu yang optimal. Petani ubi kayu masih memiliki peluang meningkatkan produksi sebesar o,oo24 dengan cara pengkombinasian faktorfaktor produksi melalui penambahan faktor produksi tenaga kerja dan bibit serta mengurangi faktor produksi pupuk. Kondisi tersebut sesuai dengan penelitian yang dilakukan oleh Ochi et al. (2015) berjudul "Economic Analysis of Resource Use Efficiency among Small Scale Cassava Farmers in Nasarawa State, Nigeria: Implications for Agricultural Transformation Agenda”. Hasil penelitian menunjukkan usahatani ubi kayu di daerah penelitian belum efisien berdasarkan aspek teknis, karena hasil penghitungan sebesar o,893. Hasil penghitungan efisiensi harga faktor produksi luas lahan menunjukkan 
Usaha tani ubi kayu di daerah penelitian belum efisien berdasarkan aspek teknis, karena hasil penghitungan sebesar o,893. Hasil penghitungan efisiensi harga faktor produksi luas lahan menunjukkan penggunaan faktor produksi luas lahan pada usahatani kayu tidak efisien berdasarkan aspek harga. Penggunaan faktor produksi luas lahan yang tidak efisien berdasarkan aspek harga disebabkan belum optimalnya penggunaan faktor produksi tenaga kerja, bibit dan pupuk pada usahatani ubi kayu, pengurangan dapat dilakukan pada faktor produksi lain seperti pupuk atau melakukan penambahan faktor produksi tenaga kerja dan bibit

Tabel 3. Hasil Penghitungan Efisiensi Harga Faktor-Faktor Produksi pada Usahatani Ubi Kayu

\begin{tabular}{|c|c|c|c|}
\hline No. & Faktor Produksi & $\begin{array}{l}\text { Efisiensi } \\
\text { Harga }\end{array}$ & Hasil \\
\hline 1. & Luas Lahan (Xl) & 0,0906 & $\begin{array}{l}\text { Tidak } \\
\text { Efisien }\end{array}$ \\
\hline 2. & Tenaga Kerja $\left(\mathrm{X}_{2}\right)$ & 1,7547 & $\begin{array}{l}\text { Belum } \\
\text { Efisien }\end{array}$ \\
\hline 3. & $\operatorname{Pupuk}\left(\mathrm{X}_{3}\right)$ & 0,6856 & $\begin{array}{l}\text { Tidak } \\
\text { Efisien }\end{array}$ \\
\hline 4. & Bibit $\left(X_{4}\right)$ & 22,2572 & $\begin{array}{l}\text { Belum } \\
\text { Efisien }\end{array}$ \\
\hline 5 & $\begin{array}{l}\text { Efisiensi } \\
(\mathrm{EH})\end{array}$ & 4,0926 & $\begin{array}{l}\text { Belum } \\
\text { Efisien }\end{array}$ \\
\hline
\end{tabular}

Sumber : Data Primer Diolah, 2016

Sementara itu, hasil penghitungan efisiensi harga faktor produksi tenaga kerja menunjukkan penggunaan faktor produksi tenaga kerja belum efisien berdasarkan aspek harga. Petani ubi kayu dapat menambah penggunaan tenaga kerja terutama pada masa tanam dan masa perawatan agar efisiensi harga pada faktor produksi tenaga kerja tercapai. Hasil penghitungan efisiensi harga faktor produksi pupuk menunjukkan bahwa penggunaan faktor produksi pupuk tidak efisien berdasarkan aspek harga. Petani dapat mengurangi penggunaan faktor produksi pupuk agar efisiensi harga pada faktor produksi pupuk tercapai. Sedangkan hasil penghitungan efisiensi harga faktor produksi bibit menunjukkan bahwa penggunaan faktor produksi bibit pada usaha tani ubi kayu belum efisien berdasarkan aspek harga. Sehingga petani ubi kayu dapat menambah penggunaan faktor produksi bibit

Hasil penghitungan efsisensi harga menunjukkan bahwa penggunaan faktorfaktor produksi pada usahatani ubi kayu belum efisien berdasarkan aspek harga. Berdasarkan kondisi tersebut, maka petani ubi kayu dapat mengoptimalkan penggunaan faktor-faktor produksi melalui penambahan faktor produksi tenaga kerja dan bibit serta mengurangi penggunaan pupuk. Kondisi tersebut sesuai dengan penelitian yang dilakukan oleh Setiawan dan Prajanti (2011) yang berjudul "Analisis Efisiensi Penggunaan Faktor-Faktor Produksi Usaha Tani Jagung di Kabupaten Grobogan Tahun 2008”. Hasil penelitiannya menunjukkan bahwa usahatani jagung di Kabupaten Grobogan belum efisien berdasarkan aspek harga karena hasil penghitungannya sebesar 1,53563 .

Hasil penghitungan efisiensi ekonomi sebesar 4,0828, menunjukkan bahwa dalam penggunaan faktor-faktor produksi pada usahatani ubi kayu belum efisien berdasarkan aspek ekonomi. Penggunaan faktor-faktor produksi pada usahatani ubi kayu belum tercapai efisiensi ekonomi disebabkan 
penggunaan faktor produksi tenaga kerja yang pada kenyataannya ditemukan bahwa penggunaannya kurang dari $40 \mathrm{HOK}$ per hektare, hal tersebut terjadi karena anggapan petani bahwa tenaga kerja cukup dari keluarga petani sendiri. Pada faktor produksi bibit kenyataannya ditemukan bahwa penggunaan bibit masih kurang dari 10.000 batang per hektare, hal tersebut terjadi karena petani belum menggunakan perhitungan dalam penanaman bibit. Kendala lain yang dihadapi petani adalah penggunaan pupuk, meskipun jumlah pupuk ang digunakan sebagian petani berkisar 201-40o Kg, akan tetapi masih mengakibatkan ambruknya tanaman ubi kayu sehingga produksi optimal belum tercapai. Kondisi tersebut sesuai dengan penelitian yang dilakukan oleh Prajanti dan Soesilowati (2012) berjudul "The Policy Effectiveness of "Go Organic": A Study Implementation and Efficiency of Organic Vegetable Cultivation in Semarang Municipality". Hasil penelitiannya menunjukkan bahwa usahatani sayur organik di Kotamadya Semarang masih jauh dari efisien, karena hasil penghitungan efisiensi ekonomi diperoleh nilai sebesar 2,705. Penelitian tersebut didudkung dengan penelitian yang dilakukan oleh Miftachuddin (2014) berjudul "Analisis Efisiensi FaktorFaktor Produksi Usahatani Padi di Kecamatan Undaan Kabupaten Kudus" hasil penelitiannya menunjukkan bahwa usahatani padi di Kabupaten Kudus belum efisien berdasarkan aspek ekonomi karena hasil penghitungannya sebesar 21,04.

\section{SIMPULAN}

Berdasarkan penelitian yang dilakukan maka dapat ditarik kesimpulan bahwa faktor produksi luas lahan, tenaga kerja, pupuk dan bibit berpengaruh positif terhadap produksi ubi kayu di Kabupaten Pati. Penggunaan faktor-faktor produksi pada usahatani ubi kayu di Kabupaten Pati belum tercapai efisiensi teknis, efisiensi harga dan efisiensi ekonomi.

\section{DAFTAR PUSTAKA}

Badan Pusat Statistik Provinsi Jawa Tengah. 2015. Jawa Tengah Dalam Angka 2015. Semarang: Badan Pusat Statistik.

Badan Pusat Statistik Kabupaten Pati. 2015. Kabupaten Pati Dalam Angka 2015. Kabupaten Pati: Badan Pusat Statistik.

Daniel, Moehar. 2002. Pengantar Ekonomi Pertanian. Jakarta: PT. Bumi Aksara.

Food and Agriculture Organization of the United Nations. 2015. Food Outlook October 2015. Roma: United Nations.

Joesron, Tati Suhartati dan Fathorrazi. 2003. Teori Ekonomi Mikro. Jakarta: Salemba Empat.

Miftachuddin, Arif. 2014. Analisis Efisiensi Faktor-Faktor Produksi Usahatani Padi di Kecamatan Undaan Kabupaten Kudus. Dalam Economic Development Analysis Journal (EDAJ), 1(1): 1-12.

Nicholson, Walter. 2002. Mikroekonomi Intermediate dan Aplikasinya. Jakarta: Erlangga.

Ochi, J.E., R.M. Sani and F.K. Idefoh. 2015. Economic Analysis of Resource Use Efficiency among Small Scale Cassava Farmers in Nasarawa State, Nigeria: Implications for Agricultural Transformation Agenda. Dalam International Journal of Research in Agriculture and Forestry, 2(2):14-21. 
Prajanti, Sucihatiningsih Dian Wisika. 2013. Metode Analisis Efisiensi Produksi dan Pengambilaan Keputusan Bidang Ekonomi Pertanian. Semarang: Unnes Press.

Prajanti, Sucihatiningsih Dian Wisika dan Etty Soesilowati. 2012. "The Policy Effectiveness of "Go Organic": A Study Implementation and Efficiency of Organic Vegetable Cultivation in Semarang Municipality”. Dalam Sociology Study, 2 (6): 468482.

Salvatore, Dominick. 1994. Teori Mikro Ekonomi Edisi Tiga. Jakarta: Erlangga.

Saptana. 2012. Konsep Efisiensi Usahatani Pangan dan Implikasinya Bagi Peningkatan Produktivitas. Dalam Forum Penelitian Agro Ekonomi, 30(2): 109-128. Bogor: Pusat Sosial Ekonomi dan Kebijakan Pertanian.
Sukirno, Sadono. 2005. Teori Pengantar Mikro Ekonomi. Jakarta: PT. Raja Grafindo Persada.

Setiawan, Avi Budi dan Sucihatiningsih Dian Wisika Prajanti. 2011. Analisis Efisiensi Penggunaan Faktor-Faktor Produksi Usaha Tani Jagung di Kabupaten Grobogan Tahun 2008. Dalam Jurnal Ekonomi dan Kebijakan (JEJAK), 4(1): 69-75.

Setiawan, Didit Heru dan Agus Andoko. 2005. Petunjuk Lengkap Budidaya Karet. Jakarta: PT. Agromedia Pustaka.

Soekartawi. 2001. Agribisnis, Teori dan Aplikasinya. Jakarta: Raja Grafindo Persada.

Suparyono dan Agus Setyono. 1993. Padi. Jakarta: PT. Penebar Swadaya. 


\section{LAMPIRAN}

Tabel 1 Luas Panen, Produksi dan Produktivitas Ubi Kayu di Provinsi Jawa Tengah Tahun 2013-2014

\begin{tabular}{|c|c|c|c|c|c|c|}
\hline \multirow{2}{*}{ Kabupaten/Kota } & \multicolumn{2}{|c|}{ Luas Panen (ha) } & \multicolumn{2}{|c|}{ Produksi (Ton) } & \multicolumn{2}{|c|}{ Produktifitas(Kw/ha) } \\
\hline & 2013 & 2014 & 2013 & 2014 & 2013 & 2014 \\
\hline Kab. Cilacap & 5,093 & 4381 & 174,364 & $113015 \cdot 35$ & 342.36 & $257 \cdot 97$ \\
\hline Kab. Banyumas & 3,206 & 2987 & 78,688 & 43049.64 & $245 \cdot 44$ & 144.12 \\
\hline Kab. Purbalingga & 3,608 & 3304 & 92,604 & 93284.91 & 256.66 & 282.34 \\
\hline Kab. Banjarnegara & 8,928 & 8400 & 244,979 & 204511.12 & $274 \cdot 39$ & 243.47 \\
\hline Kab. Kebumen & 4,703 & 5436 & 140,864 & 124660.29 & $299 \cdot 5^{2}$ & $229 \cdot 32$ \\
\hline Kab. Purworejo & 3,689 & 5489 & 93,108 & $142144 \cdot 34$ & 252.39 & 258.96 \\
\hline Kab. Wonosobo & 6,182 & 6880 & 195,754 & 256686.66 & 316.65 & 373.09 \\
\hline Kab. Magelang & 2,102 & 2070 & 63,189 & 85420.65 & 300.61 & 412.66 \\
\hline Kab. Boyolali & 4,904 & 5057 & 82,562 & 94321.90 & 168.36 & $186.5^{2}$ \\
\hline Kab. Klaten & 639 & 698 & 14,711 & 14700.96 & 230.23 & 210.62 \\
\hline Kab. Sukoharjo & 2,116 & 1600 & 36,868 & $27864 \cdot 33$ & 174.23 & 174.15 \\
\hline Kab. Wonogiri & 56,803 & 51656 & $1,062,144$ & 1041880.47 & 186.99 & 201.70 \\
\hline Kab. Karanganyar & 4,892 & 4324 & 116,226 & 127873.23 & $237 \cdot 58$ & $295 \cdot 73$ \\
\hline Kab. Sragen & 2,836 & 2491 & 83,380 & 44738.23 & 294.01 & 179.60 \\
\hline Kab. Grobogan & 1,564 & 1272 & 37,780 & 28186.93 & 241.56 & 221.60 \\
\hline Kab. Blora & 3,069 & 2482 & 85,149 & 68516.59 & $277 \cdot 45$ & 276.05 \\
\hline Kab. Rembang & 6,275 & 4815 & 150,203 & 129330.11 & $239 \cdot 37$ & 268.60 \\
\hline Kab. Pati & 16,163 & 17871 & 698,325 & 744745.69 & 432.05 & 416.73 \\
\hline Kab. Kudus & 1,476 & 1488 & 38,185 & 34121.64 & 258.70 & $229 \cdot 31$ \\
\hline Kab. Jepara & 10,151 & 9073 & 320,201 & 305105.45 & 315.44 & 336.28 \\
\hline Kab. Demak & 479 & 428 & 10,375 & 9406.21 & 216.59 & $219 \cdot 77$ \\
\hline Kab. Semarang & 1,955 & 1822 & 50,012 & 34812.34 & 255.82 & 191.07 \\
\hline Kab. Temanggung & 2,461 & 1739 & 62,314 & 52638.24 & 253.20 & 302.69 \\
\hline Kab. Kendal & 985 & 694 & 21,409 & 21208.10 & $217 \cdot 35$ & $305 \cdot 59$ \\
\hline Kab. Batang & 1,385 & 1825 & 34,538 & 47454.27 & $249 \cdot 37$ & 260.02 \\
\hline Kab. Pekalongan & 681 & 504 & 11,441 & 7860.74 & 168.01 & $155 \cdot 97$ \\
\hline Kab. Pemalang & 2,239 & 1415 & 25,710 & $26043 \cdot 72$ & 114.83 & 184.05 \\
\hline Kab. Tegal & 578 & 517 & 13,015 & 12092.33 & 225.18 & 233.89 \\
\hline Kab. Brebes & 1,811 & 1872 & 35,258 & 27860.16 & 194.69 & 148.83 \\
\hline Kota Magelang & 3 & 2 & 42 & 28.65 & 140.09 & 143.24 \\
\hline Kota Surakarta & 13 & 9 & 176 & 121.00 & 135.00 & 134.44 \\
\hline Kota Salatiga & 260 & 180 & 6,226 & 6473.80 & 239.47 & 359.66 \\
\hline Kota Semarang & 534 & 420 & 9,834 & 7652.22 & 184.16 & 182.20 \\
\hline
\end{tabular}

Sumber : BPS Provinsi Jawa Tengah (2015) 